\title{
Accuracy of 99mTc (V)-Dimercaptosuccinic Acid Scintigraphy and Fecal Calprotectin Compared with Colonoscopy in Localizing Active Lesions in Inflammatory Bowel Disease
}

\author{
Vahid Basirat ${ }^{1}$, Zahra Azizi², Sanam Javid Anbardan ${ }^{3}$, Mina Taghizadeh Asl ${ }^{4}$, \\ Yasaman Farbod $^{5}$, Azam Teimouri ${ }^{6}$, Nasser Ebrahimi Daryani ${ }^{7 *}$
}

1. Internal Medicine Resident, Tehran University of Medical Science, Tehran, Iran.

2. Researcher, Iran University of Medical Sciences, Tehran, Iran.

3. Researcher, Tehran University of Medical Sciences, Tehran, Iran.

4. Nuclear Medicine Physician, Head of Nuclear Medicine Department, Kasra General Hospital, Tehran, Iran.

5. Tehran University of Medical Sciences, Tehran, Iran.

6. Assistant Professor of Isfahan University of Medical Sciences, Isfahan, Iran.

7. Professor, Department of Internal Medicine, Division of Gastroenterology, Imam Khomeini Hospital, Tehran University of Medical Sciences, Tehran, Iran.

* Corresponding Author: Nasser Ebrahimi Daryani, MD Floor 2, no.130, Shahid Naseri Street, Valiasr Ave., Tehran, Iran Telefax : + 982188793896 Email: nebrahim@sina.tums.ac.ir

Received: 03 Feb. 2016

Accepted: 11 May 2016

\section{ABSTRACT}

\section{INTRODUCTION}

Due to limitation of colonoscopy in assessing the entire bowel and patients' intolerance in inflammatory bowel disease (IBD), in the current study, we aimed to prospectively compare the accuracy of ${ }^{99 \mathrm{~m}} \mathrm{Tc}(\mathrm{V})$-dimercaptosuccinic acid (DMSA) and fecal calprotectin with ileocolonoscopy as new methods for localizing inflammations.

\section{METHODS}

Current prospective study conducted between 2012 and 2014 on 30 patients with IBD attending Gastroenterology Clinic of Tehran University of Medical Sciences. Fecal calprotectin and disease activity were measured for all participants and all of them underwent ${ }^{99 \mathrm{~m}} \mathrm{Tc}(\mathrm{V})$-DMSA scintigraphy and colonoscopy. The accuracy of ${ }^{99 \mathrm{~m}} \mathrm{Tc}(\mathrm{V})$ DMSA scintigraphy and calprotectin in localizing bowel lesions were calculated.

\section{RESULTS}

A total of 22 patients with ulcerative colitis (UC) and 8 patients with Crohn's disease (CD) were evaluated in our study. Sensitivity, positive likelihood ratio (PLR), and positive predictive value (PPV) of scintigraphy and calprotectin over colonoscopy in localization of UC lesions were $86.36 \%, 0.86 \%, 100.00 \%$ and $90.91 \%, 0.91$, and $100.00 \%$, respectively. Meanwhile, it showed $66.67 \%$ sensitivity and $81.25 \%$ specificity with PLR $=3.56$, negative likelihood ratio $(\mathrm{NLR})=0.41, \mathrm{PPV}=84.21 \%$, and negative predictive value $(\mathrm{NPV})=$ $61.90 \%$ in localizing lesions in patients with CD. The calprotectin level had sensitivity, PLR, and PPV of $90.00 \%, 0.90$, and $100.00 \%$ in detecting active disease over colonoscopy, respectively.

\section{CONCLUSION}

The ${ }^{99 m} \mathrm{Tc}(\mathrm{V})$-DMSA scintigraphy would be an accurate method for detecting active inflammation in follow-up of patients with IBD and assessing response to treatment as a non-invasive and complementary method beside colonoscopy for more accurate diagnosis of $\mathrm{CD}$ or $\mathrm{UC}$

\section{KEYWORDS}

${ }^{99 m} \mathrm{Tc}(\mathrm{V})-\mathrm{DMSA}$ scintigraphy; Inflammatory bowel disease; Clinical findings; Colonoscopy

Please cite this paper as:

Basirat V, Azizi Z, Javid Anbardan S, Taghizadeh Asl M, Farbod Y, Teimouri A, Ebrahimi Daryani N. Accuracy of 99mTc (V)-Dimercaptosuccinic Acid Scintigraphy and Fecal Calprotectin Compared with Colonoscopy in Localizing Active Lesions in Inflammatory Bowel Disease. Middle East J Dig Dis 2016;8:212-218. DOI:10.15171/mejdd.2016.23

\section{INTRODUCTION}

Chronic inflammatory bowel disease (IBD) mainly has two subtypes; Crohn's disease (CD) and ulcerative colitis (UC). While UC mainly involves colon, $\mathrm{CD}$ can affect all sections of gastrointestinal tract. In 
recent years, because of life style modifications, the incidence of IBD has increased. ${ }^{1-5}$ Although IBD can have various clinical presentations, persistent or recurrent abdominal pain and diarrhea are the most common manifestations. Anemia, weight loss, and rectal bleeding are the other presentations. ${ }^{6}$

Currently, clinical, endoscopic, radiological, and biochemical investigations are combined for IBD diagnosis and follow up among which ileocolonoscopy with tissue sampling is the gold standard., $2,6-9$ The best method for follow-up of patients with IBD is one of the most important challenges. On the one hand, patients with IBD require long-term monitoring because of the chronic nature of the disease and frequent flares and remissions. ${ }^{10,11}$ On the other hand, endoscopy is not tolerated well by these patients due to difficulty of bowel preparation and occurrence of complications. ${ }^{7,12-14}$

Thus, other methods including fecal calprotectin level and scintigraphy have been developed to monitor the activity and severity of the disorder. ${ }^{8,9}$ Measuring fecal calprotectin - calcium and zinc binding protein originating from inflammatory cellsby enzyme-linked immunosorbent assay methods (ELISA) is a sensitive marker for diagnosing intestinal inflammation and also has a good correlation with endoscopic and microscopic activity of the disease. ${ }^{15-19}$ Likewise, scintigraphic imaging is also reliable in diagnosis and evaluation of disease activity as a non-invasive method especially when using radiolabeled leukocytes, which is more popular, because of higher sensitivity and specificity. However, the high cost and high dose of radiation are the main drawbacks of this method. ${ }^{9,20-23}$

Theoretically, low cost, high image quality, and easy preparation make pentavalent technetium-99mdimercaptosuccinic acid $\left({ }^{99 \mathrm{~m}} \mathrm{Tc}(\mathrm{V})-\mathrm{DMSA}\right)$ an attractive practical method for investigating inflammatory processes; however, few studies have evaluated its efficacy in IBD. ${ }^{23-25}$

In the current study, we aimed to prospectively compare the sensitivity, specificity, and accuracy of ${ }^{99 \mathrm{~m}} \mathrm{Tc}(\mathrm{V})$-DMSA and fecal calprotectin with ileocolonoscopy for diagnosis of IBD and monitoring its activity.

\section{MATERIALS AND METHODS}

This single-center prospective study was approved by Ethics Committee of Tehran University of Medical Sciences (TUMS). Between 2012 and 2014, 30 participants were recruited from Gastroenterology Clinic of Imam Khomeini Hospital affiliated to TUMS.

\section{Participants and study design}

After obtaining informed consent, 30 symptomatic patients with IBD (21women and 9 men; range: 18-65 years) who were diagnosed by colonoscopy and biopsy sampling were enrolled. The initial diagnoses were UC and CD in 22 (16 women, 6 men) and eight (five women and three men) patients, respectively. Female patients who were pregnant and lactating were excluded from the study.

Then a standard investigation was performed, which included obtaining medical history, physical examination, measuring C-reactive protein (CRP), erythrocyte sedimentation rate (ESR), and fecal calprotectin followed by clinical assessment of disease activity by CD Activity Index (CDAI), Mayo score, and Harvey-Bradshaw index. The disease was considered clinically active in patients with $\mathrm{CD}$ if CDAI scores were higher than 150 .

Then, all the cases underwent further diagnostic evaluations as well as ${ }^{99 \mathrm{~m}} \mathrm{Tc}(\mathrm{V})$-DMSA scintigraphy and colonoscopy. Each test was interpreted regardless of findings in the other test.

During the diagnostic assessments, the patients' pharmacological treatments were not subject to any change.

\section{Reference study}

The reference investigation was colonoscopy by a brand colonoscope (Olympus 190-series,USA) in which an experienced endoscopist blind to the results of the scintigraphy evaluated the colon following the standard preparation protocol (colonic cleansing with $4 \mathrm{~L}$ polyethylene glycol plus low-fiber diet 3 days before investigation).

The inflammatory lesions at endoscopy were evaluated based on the scale of 0-3 described by Gomes and colleagues. ${ }^{26}$ In this scale, $0,1,2$, and 3 stand 
for normal, presence of mild inflammation with loss of vascular pattern, severe inflammation with contact bleeding, and more severe disease with friability, ulcers, or spontaneous bleeding, respectively.

\section{${ }^{99 m}$ Te (V)-DMSA Scintigraphy and Interpretation of Findings}

All patients received intravenous injection of 20 microcuries of (740 MBq) ${ }^{99 \mathrm{~m}} \mathrm{Tc}(\mathrm{V})-\mathrm{DMSA}$, which were prepared by a commercial (V)-DMSA kit (Parsisotope, Iran).

Starting at minute one, the scans were done in dynamic mode for 30 minutes. Subsequently, at 60 , 120 , and 180 minutes after the injection, the anterior planar projections of the abdomen and pelvis were attained, each for a10-minute duration. A gamma camera (E.cam, Siemens, Germany) equipped with a low-energy general-purpose collimator was used for scintigraphy. The radiotracer uptake distribution was recorded in each scan. Two nuclear medicine specialists unaware of the clinical diagnosis and endoscopic findings evaluated the scintigraphic data.

The bowel was divided into following five segments: rectosigmoid (RS), descending colon (DC), transverse colon (TC), ascending colon (AC), and small bowel. Any distinct center of uptake in any parts of the bowel on the scintigraphy was considered as a positive finding.

Same specialists assessed the severity of the disease by comparing the intensity of the uptake with the uptake in the iliac crest and scored it as following: score $0=$ no uptake, score $1=$ uptakes less than iliac crest bone marrow, score $2=$ moderate uptake equivalent to iliac crest, and score $3=$ severe uptake greater than iliac crest.

The inter-observer variability was $81 \%$ with Kappa of $63 \%$ and then any disagreement was fixed by discussion. Finally, the scintigraphic results were compared with clinical data, fecal calprotectin levels, and endoscopic findings.

\section{Statistical analysis}

Descriptive statistics were performed for colonos- copy, ${ }^{99 \mathrm{~m}} \mathrm{Tc}$ (V)-DMSA scintigraphy, stool calprotectin level, and serum hemoglobin $(\mathrm{Hb})$ level results. A comparison at the level of each different segment was derived between the lesions found at ${ }^{99 \mathrm{~m}} \mathrm{Tc}(\mathrm{V})$ DMSA scintigraphy, ileocolonoscopy, and calprotectin level by cross tab and Chi square test. Sensitivity, specificity, positive likelihood ratio (PLR), negative likelihood ratio (NLR), positive predictive value (PPV), and negative predictive value (NPV) of ${ }^{99 m}$ Tc (V)-DMSA scintigraphy and calprotectin in localization of lesions of all segments were determined on a per-segment (for CD patients) and overall basis (for UC patients). Correlation between variables was determined by spearman or Pearson test. All the statistical analyses were performed using the SPSS software (version 18). $p$ value $<0.05$ was considered as statistically significant.

\section{RESULTS:}

A total of 30 patients (22 [73.3\%] patients with UC and 8 [26.7\%] patients with CD) consisting of 19 men $(63.3 \%)$ and 11 women $(36.7 \%)$ were enrolled in our study and assessed by colonoscopy and ${ }^{99 \mathrm{~m}} \mathrm{Tc}(\mathrm{V})$-DMSA Scintigraphy.

\section{Patients with UC:}

The UC group included $16(72.7 \%)$ men and 6 $(27.3 \%)$ women. The median and mean disease duration was about 4 and $7.27 \pm 7.17$ (1-23) years, respectively. The median calprotectin level was 1875.00 with a mean level of 1585.45 \pm 617.89 (0-2000), which was high in all but two patients. Median Mayo score was 9 with mean level of $9.40 \pm 2.32$ (5-12), which demonstrated moderate to severe disease except in one patient with mayo score 5 that showed mild disease.

Median $\mathrm{Hb}$ level was $13.55(\mathrm{gr} / \mathrm{dl})$ with mean level of $12.81 \pm 2.60(5.70-16.70) .10(45.5 \%)$ patients had normal level of $\mathrm{Hb}$ while $9(40.9 \%)$ and $3(13.6 \%)$ patients had mild and severe level of $\mathrm{Hb}$, respectively. $\mathrm{Hb}$ level was correlated with Mayo score by Pearson's test with $r$ $=-0.381$ and $p$ value $=0.08$.

The result of Tc99 DMSA scintigraphy showed lesions in $19(86.4 \%)$ segments while $3(13.6 \%)$ segments did not have lesions. All the 19 positive segments were true. All 3 negative results were false negative. Gener- 
Table 1: Sensitivity, Specificity, positive likelihood ratio (PLR), Negative likelihood ratio (NLR), Positive Predictive Value (PPV), and Negative Predictive Value (NPV) of Technetium-99m (V) DMSA Scintigraphy in the Localization of Lesions, Calculated for Each Segment

\begin{tabular}{|c|c|c|c|c|c|c|}
\hline Colonic segment & Sensitivity & Specificity & PLR & NLR & PPV & NPV \\
\hline $\begin{array}{l}\text { Total number of } \\
\text { colonic segment } \\
\mathrm{N}=240\end{array}$ & $\begin{array}{c}66.67 \\
(44.68-84.37)\end{array}$ & $\begin{array}{c}81.25 \\
(54.35-95.95)\end{array}$ & $\begin{array}{c}3.56 \\
(1.23-10.25)\end{array}$ & $\begin{array}{c}0.41 \\
(0.220 .76)\end{array}$ & $\begin{array}{c}84.21 \\
(60.42-96.62)\end{array}$ & $\begin{array}{c}61.90 \\
(38.44-81.89)\end{array}$ \\
\hline $\begin{array}{l}\text { Small intestine } \\
n=8\end{array}$ & $\begin{array}{c}0 \\
(0-84.19)\end{array}$ & $\begin{array}{c}100 \\
(54.07-100)\end{array}$ & - & 1 & - & $\begin{array}{c}75 \% \\
(34.91-96.81)\end{array}$ \\
\hline $\begin{array}{c}\begin{array}{c}\text { Descending colon } \\
n=8\end{array} \\
\text {. }\end{array}$ & $\begin{array}{c}83.33 \\
(35.88-99.58)\end{array}$ & $\begin{array}{c}100 \\
(15.81-100)\end{array}$ & - & $\begin{array}{c}0.17 \\
(0.03-1.00)\end{array}$ & $\begin{array}{c}100 \\
(47.82-100)\end{array}$ & $\begin{array}{c}66.67 \\
(9.43-99.16)\end{array}$ \\
\hline $\begin{array}{l}\begin{array}{c}\text { Ascending colon } \\
n=8\end{array} \\
\text { a }\end{array}$ & $\begin{array}{c}71.43 \\
(29.04-96.33)\end{array}$ & $\begin{array}{c}0 \\
(0-97.50)\end{array}$ & $\begin{array}{c}0.71 \\
(0.45-1.14)\end{array}$ & - & $\begin{array}{c}83.33 \\
(35.88-99.58)\end{array}$ & - \\
\hline $\begin{array}{c}\text { Transverse colon } \\
\quad \mathrm{n}=8\end{array}$ & $\begin{array}{c}33.33 \\
(0.84-90.57)\end{array}$ & $\begin{array}{c}60 \\
(14.66-94.73)\end{array}$ & $\begin{array}{c}0.83 \\
(0.12-5.72)\end{array}$ & $\begin{array}{c}1.11 \\
(0.38-3.25)\end{array}$ & $\begin{array}{c}33.33 \\
(0.84-90.57)\end{array}$ & $\begin{array}{c}60 \\
(14.66-94.73)\end{array}$ \\
\hline $\begin{array}{c}\text { Rectosigmoid } \\
\mathrm{n}=8\end{array}$ & $\begin{array}{c}83.33 \\
(35.88-99.58)\end{array}$ & $\begin{array}{c}100 \\
(15.81-100)\end{array}$ & - & $\begin{array}{c}0.17 \\
(0.03-1.00)\end{array}$ & $\begin{array}{c}100 \\
(47.82-100)\end{array}$ & $\begin{array}{c}66.67 \\
(9.43-99.16)\end{array}$ \\
\hline
\end{tabular}

ally, sensitivity, PLR, PPV, and K of Tc99 DMSA scintigraphy in localization of UC lesions were $86.36 \%$ (65.09\%-97.09\%) , $0.86,100.00 \%(82.35 \%-100.00 \%)$, and $0.78(\mathrm{P}<0.001)$, respectively. Correlation between Mayo score and calprotectin level with Spearman test showed $r=0.43$ and $p$ value $=0.042$.

The sensitivity, PLR, PPV, and $\mathrm{K}$ of calprotectin level over colonoscopy were calculated to be $90.91 \%$ (70.84\%-98.88\%) , 0.91 , and 100.00\% ( 83.16\%$100.00 \%$ ) in detecting the active disease, respectively . The aforementioned values were found to be $85.00 \%$ (62.11\%-96.79\%), 0.85, and 89.47\% (66.86\%-98.70\%) for Tc99 DMSA scintigraphy over calprotectin in detection of active disease, respectively. Meanwhile, the $\mathrm{Hb}$ level was correlated with the Mayo score assessed by Pearson's test $(r=-0.381, p$ value $=0.08)$.

\section{Patients with CD:}

Patients with CD (three [37.5\%] men, five [62.5\%] women) had median disease duration of 3 years and mean duration of $7.62 \pm 8.79$ (1-23) years. The median and mean

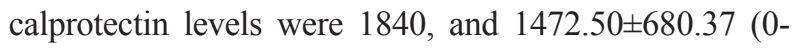
1950), respectively. The levels were high in all patients but one. The median CDAI score was 277.80 with a mean level of $304.00 \pm 206.05$ (57-730) reflecting severe disease in one $(12.5 \%)$, moderate to severe disease in four $(50 \%)$, asymptomatic remission in two $(25 \%)$, and mild to moderate disease in one (12.5\%). The Harvey Bradshaw index showed a median of 6 with mean level of $9.12 \pm 11.48$
(1-37), which showed active CD in six (75\%) patients and clinical remission in two (25\%) patients. Median $\mathrm{Hb}$ level of the patients were 11.85 with mean level of $11.98 \pm 3.50$ (7.6-16.10) that showed normal level in four (50\%), mild in one $(12.5 \%)$, and severe level in three $(37.5 \%)$ patients.

We performed per segment analysis for five regions (small intestine, ascending colon, descending colon, transverse colon and rectosigmoid), in eight patients with CD (table 1). The result of ${ }^{99 \mathrm{~m}} \mathrm{Tc}(\mathrm{V})$-DMSA scintigraphy showed lesions in 19 (47.5\%) segments while $21(52.5 \%)$ segments were reported negative. Among the 19 positive lesions $16(84.21 \%)$ were true positive and $3(15.79 \%)$ were false positive. Amongst 21 negative results, $13(61.90 \%)$ and $8(30.10 \%)$ segments were true and false negative, respectively. Generally sensitivity, specificity, PLR, NLR, PPV, and NPV of ${ }^{99 \mathrm{~m}} \mathrm{Tc}$ (V)DMSA scintigraphy were $66.67 \%$ (44.68\%-84.37\%), $81.25 \%$ (54.35\%-95.95\%), 3.56 (1.23-10.25), 0.41(0.22$0.76), 84.21(60.42-96.62)$, and 61.90(38.44-81.89), respectively in localization of lesions in the five regions.

Even though the calprotectin level had sensitivity, PLR, and PPV of $90.00 \%$ (73.47\%-97.89\%) , 0.90 , and $100.00 \%(87.23 \%-100.00 \%)$ in detecting active disease over colonoscopy, respectively. The aforementioned values were $100 \%$ (59.04-100\%), 1 , and 87.50\% (47.35\%99.68\%) for Tc99 (V) DMSA scintigraphy over calprotectin in detection of active disease, respectively.

The Spearman's test showed a correlation between CDAI score and Harvey Bradshaw index with calprotec- 
tin level $(\mathrm{r}=0.68, \mathrm{P}$ value $=0.06$ and $\mathrm{r}=0.74 \mathrm{P}$ value $=0.03$, respectively). The CDAI test was significantly correlated with AC uptake $(r=0.73, p$ value $=0.039)$ however its correlation with TC uptake $(r=-0.071, p$ value $=0.86), \mathrm{DC}$ uptake $(r=0.43, p$ value $=0.28)$ and $\mathrm{RS}$ uptake $(r=0.61, p$ value $=0.10)$ was not statistically significant. Besides, the correlation between Mayo score and ${ }^{99 \mathrm{~m}} \mathrm{Tc}$ (V) DMSA scintigraphic score was not significant. Likewise the correlation between CDAI $(r=-0.45, p$ value $=0.26)$ and Harvey Bradshaw index $(r=-0.68, p$ value $=0.06)$ with $\mathrm{Hb}$ level was not statistically significant.

\section{DISCUSSION:}

Different types of radionucleotide scintigraphy methods have been assessed for identifying inflammation in gastrointestinal tract. Although $67 \mathrm{Ga}$ is one of the primary techniques, it bears some restrictions including excretion to gastrointestinal tract and disguising the inflammatory zones and giving a false positive result. Meanwhile, long processing time of $67 \mathrm{Ga}$ makes it inappropriate for evaluating acute conditions. When it comes to human immunoglobulin, the accuracy of chemotactic peptides, labeled anti-granulocyte monoclonal antibodies, labeled anti-granulocyte monoclonal antibodies, simple colloids phagocytosed by leukocytes and labeled anti-E-selectin monoclonal antibodies, are impaired due to non-specific selectivity of their attachment to the inflammation zones and insufficient uptakes. ${ }^{1,9,23,24,27}$

Firstly in 1981 Yokoyama and colleagues introduced 99mTc (V)-DMSA 28 for diagnosis of malignant tumors and metastases. Later this method was applied for evaluating osteomyelitis, fractures, benign tumors, psoas muscle abscess, and bone and joint infections as well as inflammations. ${ }^{23,24,29-33}$

The higher accuracy of ${ }^{99 \mathrm{~m}} \mathrm{Tc}(\mathrm{V})$-DMSA scintigraphy (about 90\%) and its capability for evaluating the whole bowel in association with no need to bowel preparation, non-invasiveness, cost effectiveness, and good diagnostic sensitivity (according to the results of our study and others) compared with the reported accuracy of $89 \%$ for colonoscopy and its limitation in assessment of the entire bowel, makes the former method an accurate device for assessing IBD activity. ${ }^{1,23,24}$

Although leukocyte labeling and ${ }^{99 \mathrm{~m}} \mathrm{Tc}$ hexamethyl-propyleneamine oxime white blood cell single photon emis- sion computed tomographic imaging have been identified as methods for assessing disease activity in IBD, its recurrence in postoperative patients with $\mathrm{CD}$, and response to treatment in IBD patients; prolonged processing time has prevented these methods to be used widely and studies are done to find simple, non-invasive, less costly methods. ${ }^{24}$ The results of our study showed high accuracy for ${ }^{99 \mathrm{~m}} \mathrm{Tc}$ (V)-DMSA scintigraphy in assessing inflammation in IBD. We analyzed and compared the results of ${ }^{99 \mathrm{~m}} \mathrm{Tc}$ (V)-DMSA scintigraphy and colonoscopy in CD and UC. The novelty of our study was to compare the accuracy of clinical, radiological, and colonoscopy methods for diagnosis of inflammation at the same time. In our study, a sensitivity of $86.36 \%$ and $85.00 \%$ was reported for ${ }^{99 \mathrm{~m}} \mathrm{Tc}$ (V)-DMSA scintigraphy in detecting inflammation in UC patients over colonoscopy and calprotectin level, respectively. While, calprotectin level had $90.91 \%$ sensitivity in detecting inflammation compared with colonoscopy.

Moreover, the ${ }^{99 \mathrm{~m}} \mathrm{Tc}(\mathrm{V})$-DMSA scintigraphy had $66.67 \%$ sensitivity and $81.25 \%$ specificity compared with colonoscopy and $100 \%$ over calprotectin in active disease detection while calprotectin level was reported to have a sensitivity of $90.00 \%$ over colonoscopy. To recap, ${ }^{99 \mathrm{~m}} \mathrm{Tc}$ (V)-DMSA is a potential radionucleotide scintigraphy for detecting and localizing bowel inflammations. ${ }^{23}$

In a study by Horsthuis and co-workers, different modalities for diagnosis of IBD were compared and per patients analysis scintigraphy demonstrated sensitivity and specificity of $87.8 \%$ and $84.5 \%$, respectively. Likewise the mean per-bowel segment sensitivity and specificity were reported to be $77.3 \%$ and $90.3 \%$, respectively. ${ }^{2}$

In a study by Lee and colleagues ${ }^{23}$, in Taiwan on 62 cases suspicious of having intestinal inflammation , 15, 1, and 46 patients had final diagnosis of $\mathrm{UC}, \mathrm{CD}$, and miscellaneous colitis, respectively. Moreover $95 \%$ sensitivity and 94\% specificity for detecting inflammation were reported for ${ }^{99 \mathrm{~m}} \mathrm{Tc}(\mathrm{V})$-DMSA scintigraphy. ${ }^{23}$

In another study by Koutroubakis ${ }^{24},{ }^{99 \mathrm{~m}} \mathrm{Tc}(\mathrm{V})$ DMSA scintigraphy was a useful method for identifying and localizing inflammation in intestine however it did not detect the distinct causes of inflammations.

In our study CDAI test was significantly correlated with AC uptake score of ${ }^{99 m} \mathrm{Tc}$ (V)-DMSA scintigraphy; however its correlation with TC uptake score, DC uptake 
score, and RS uptake score was not statistically significant. The correlation between Mayo score in patients with UC and ${ }^{99 m}$ Tc (V)-DMSA scintigraphic score was not significant in any of the regions. Though, in the study by Koutroubakis and co-workers ${ }^{24}$ the correlation between ${ }^{99 \mathrm{~m}} \mathrm{Tc}(\mathrm{V})$-DMSA scintigraphic score and disease activity in patient with UC and CD were reported to be significant.

Among laboratory data, none of them were correlated with ${ }^{99 \mathrm{~m}} \mathrm{Tc}(\mathrm{V})$-DMSA scintigraphic score in patients with UC and CD, except for Hb levels that were correlated with DC uptake and RS uptake in patients with CD. In the study by Koutroubakis and colleagues 24 there was a significant correlation between $\mathrm{C}$-reactive protein levels and the scintigraphic score.

They found high correlation between endoscopic and histological inflammatory activity and scintigraphic activity index. In assessing the extension of IBD, ${ }^{99 \mathrm{~m}} \mathrm{Tc}$ (V)-DMSA scintigraphy was more accurate in patients with UC than CD. Furthermore, one of the limitations of this method is its incapability in identifying mild lesions in patients with $\mathrm{CD}$. Another limitation would be the uptake by liver and bladder in the hepatic flexure. This problem could be resolved by taking the images in upright position with an empty bladder or with extra lateral views. An important limitation of our study was the lack of healthy control group that caused no negative results in standard test and we were unable to calculate specificity while comparing ${ }^{99 \mathrm{~m}} \mathrm{Tc}(\mathrm{V})$-DMSA scintigraphy with colonoscopy.

The results of the current study and reviewed literature suggest the idea that ${ }^{99 \mathrm{~m}} \mathrm{Tc}(\mathrm{V})$-DMSA scintigraphy would be an accurate method for detecting active inflammation in patients with IBD. It is not the perfect method for diagnosis of IBD; however it is a better choice for patients' follow-up and assessment of disease activity, response to treatment, along with the progression of disease. Similarly this method can be used in situations that colonoscopy is contraindicated or inappropriate or as a complementary method beside colonoscopy for more accurate diagnosis of CD or UC. However future studies are indispensable to compare this method with other diagnostic methods such as magnetic resonance enterography to find out a diagnostic method with better accuracy for diagnosis of patients with IBD.

\section{CONFLICT OF INTEREST}

The author declares no conflict of interest related to this work.

\section{REFERENCES}

1. Javadi H, Amiriani T, Mirkarimi H, Besharat S, Semnani S, Abedi J, et al. Scintigraphy with $99 \mathrm{mTc}$ (V)-DMSA in monitoring patients with inflammatory bowel disease. Hell J Nucl Med 2013;16:209-12.

2. Horsthuis K, Bipat S, Bennink RJ, Stoker J. Inflammatory bowel disease diagnosed with US, MR, scintigraphy, and CT: meta-analysis of prospective studies 1. Radiology 2008;247:64-79. doi: 10.1148/ radiol.2471070611

3. Hampe J, CuthbertA, CroucherPJ, MirzaMM, Mascheretti S, Fisher S, et al. Association between insertion mutation in NOD2 gene and Crohn's disease in German and British populations. Lancet 2001;357:1925-8. doi: 10.1016/S0140-6736(00)05063-7

4. Benchimol EI, Guttmann A, Griffiths AM, Rabeneck L, Mack DR, Brill H, et al. Increasing incidence of paediatric inflammatory bowel disease in Ontario, Canada: evidence from health administrative data. Gut 2009;58:1490-7. doi:10.1136/gut.2009.188383

5. Gismera CS, Aladrén BS. Inflammatory bowel diseases: a disease (s) of modern times? Is incidence still increasing? World J Gastroenterol 2008;14:5491-8.

6. Stange E, Travis S, Vermeire S, Beglinger C, Kupcinkas L, Geboes K, et al. European evidence based consensus on the diagnosis and management of Crohn's disease: definitions and diagnosis. Gut 2006;55:i1-15. doi:10.1136/gut.2005.081950a

7. Hommes DW, van Deventer SJ. Endoscopy in inflammatory bowel diseases. Gastroenterology 2004;126:1561-73. doi: 10.1053/j.gastro.2004.03.023

8. Van Rheenen PF, Van de Vijver E, Fidler V. Faecal calprotectin for screening of patients with suspected inflammatory bowel disease: diagnostic meta-analysis. BMJ 2010;341:c3369. doi: 10.1136/bmj.c3369.

9. Stathaki MI, Koukouraki SI, Karkavitsas NS, Koutroubakis IE. Role of scintigraphy in inflammatory bowel disease. World J Gastroenterol 2009;15:2693-700.

10. Fagerberg UL, Lööf L, Lindholm J, Hansson L-O, Finkel Y. Fecal calprotectin: a quantitative marker of colonic inflammation in children with inflammatory bowel disease. J Pediatr Gastroenterol Nutr 2007;45:414-20. doi: 10.1097/MPG.0b013e31810e75a9

11. Wu Y, Briley K, Tao X. Nanoparticle-based imaging of inflammatory bowel disease. Wiley Interdiscip Rev Nanomed Nanobiotechnol 2016;8:300-15. doi: 10.1002/wnan.1357.

12. Nikolaus S, Schreiber S. Diagnostics of inflammato- 
ry bowel disease. Gastroenterology 2007;133:167089. doi: 10.1053/j.gastro.2007.09.001

13. Gan SI, Beck P. A new look at toxic megacolon: an update and review of incidence, etiology, pathogenesis, and management. The American journal of gastroenterology 2003;98:2363-71. doi:10.1111/j.15720241.2003.07696.x

14. Aarntzen E, Hermsen R, Drenth J, Boerman O, Oyen W. Tc-99m-CXCL8 SPECT to monitor disease activity in inflammatory bowel disease. $\mathrm{J} \mathrm{Nucl} \mathrm{Med}$ 2016;57:398-403. doi: 10.2967/jnumed.115.165795.

15. Røseth A, Fagerhol M, Aadland E, Schjønsby $\mathrm{H}$. Assessment of the neutrophil dominating protein calprotectin in feces: a methodologic study. Scand J Gastroenterol 1992;27:793-8. doi:10.3109/00365529209011186

16. Tøn H, Brandsnes $\varnothing$, Dale S, Holtlund J, Skuibina $\mathrm{E}$, Schjønsby $\mathrm{H}$, et al. Improved assay for fecal calprotectin. Clin Chim Acta 2000;292:41-54. doi:10.1016/S0009-8981(99)00206-5

17. Tibble JA, Sigthorsson G, Foster R, Forgacs I, Bjarnason I. Use of surrogate markers of inflammation and Rome criteria to distinguish organic from nonorganic intestinal disease. Gastroenterology 2002;123:450-60. doi: 10.1053/gast.2002.34755

18. Carroccio A, Iacono G, Cottone M, Di Prima L, Cartabellotta F, Cavataio F, et al. Diagnostic accuracy of fecal calprotectin assay in distinguishing organic causes of chronic diarrhea from irritable bowel syndrome: a prospective study in adults and children. Clin Chem 2003;49:861-7. doi: 10.1373/49.6.861

19. Røseth A, Aadland E, Jahnsen J, Raknerud N. Assessment of disease activity in ulcerative colitis by faecal calprotectin, a novel granulocyte marker protein. Digestion 1997;58:176-80. doi:10.1159/000201441

20. Martin-Comin J, Prats E. Clinical applications of radiolabeled blood elements in inflammatory bowel disease. Q J Nucl Med 1999;43:74-82.

21. Aydın F, Dinçer D, Güngör F, Boz A, Akça S, Yıldız $A$, et al. Technetium-99m hexamethyl propylene amine oxime-labeled leukocyte scintigraphy at three different times in active ulcerative colitis: comparison with colonoscopy and clinico-biochemical parameters in the assessment of disease extension and severity. Ann Nucl Med 2008;22:371-7. doi: 10.1007/s12149-008-0131-6.

22. Cheow HK, Voutnis DD, Evans JW, Szczepura KR, Swift EA, Bird NJ, et al. Quantification of disease activity in patients undergoing leucocyte scintigraphy for suspected inflammatory bowel disease. Eur J Nucl Med Mol Imaging 2005;32:329-37. doi: 10.1007/s00259-004-1617-7

23. Lee B-F, Chiu N-T, Wu D-C, Tsai K-B, Liu G-C, Yu $\mathrm{H}-\mathrm{S}$, et al. Use of ${ }^{99 \mathrm{~m}} \mathrm{Tc}(\mathrm{V})$ DMSA Scintigraphy in the Detection and Localization of Intestinal Inflam- mation: Comparison of Findings at Colonoscopy and Biopsy. Radiology 2001;220:381-5. doi: 10.1148/ radiology.220.2.r01au30381

24. Koutroubakis IE, Koukouraki SI, Dimoulios PD, Velidaki AA, Karkavitsas NS, Kouroumalis EA. Active Inflammatory Bowel Disease: Evaluation with 99mTc (V) DMSA Scintigraphy. Radiology 2003;229:70-4. doi: 10.1148/radiol.2291020692

25. Stathaki MI, Koutroubakis IE, Koukouraki SI, Karmiris KP, Moschandreas JA, Kouroumalis EA, et al. Active inflammatory bowel disease: headto-head comparison between $99 \mathrm{mTc}$-hexamethylpropylene amine oxime white blood cells and 99mTc (V)-dimercaptosuccinic acid scintigraphy. Nucl Med Commun 2008;29:27-32. doi: 10.1097/ MNM.0b013e3282f1bc37

26. Gomes P, du Boulay C, Smith C, Holdstock G. Relationship between disease activity indices and colonoscopic findings in patients with colonic inflammatory bowel disease. Gut 1986;27:92-5. doi:10.1136/ gut.27.1.92

27. Williams C, Ford A, Poullis A. PTU-075 Systematic Review And Meta-analysis: Sensitivity And Specificity Of Tc-99m Hmpao Labelled White Cell Scintigraphy In The Diagnosis Of Active Inflammatory Bowel Disease. Gut 2014;63:A71-A. doi:10.1136/ gutjnl-2014-307263.149

28. Yokoyama A, Hata N, Horiuchi K. Chemically designed Tc-99m radiopharmaceuticals for the tumor diagnosis: Tc-99m-DMSA. J Nucl Med 1981;22:69.

29. Ohta H, Endo K, Fujita T, Konishi J, Torizuka K, Horiuchi K, et al. Clinical evaluation of tumor imaging using Tc-99m (V) dimercaptosuccinic acid, a new tumor-seeking agent. Nucl Med Commun 1988;9:105-16.

30. Guerra UP, Pizzocaro C, Terzi A, Giubbini R, Maira G, Pagliaini R, et al. New tracers for the imaging of the medullary thyroid carcinoma. Nucl Med Commun 1989;10:285-95.

31. Ohta H, Shane FI, Endo K, Torizuka K, Horiuchi $\mathrm{K}$, Yokoyama A,et al. Images of liposarcoma using technetium-99m bleomycin and technetium(V)-99m DMSA. Clin Nucl Med Commun 1986;11:842-4.

32. Ohta H, Tsuji T, Endo K, Fujita T, Konishi J, Kotoura Y,et al. SPECT images using 99mTc(V)-DMS in lung metastasis of osteosarcoma. Ann Nucl Med 1989;3:3740. doi : 10.1007/BF03164564

33. Ohnishi T, Noguchi S, Murakami N, Tajiri J, Morita M, Tamaru M, et al. Pentavalent technetium-(V)-99m DMSA uptake in a patient having multiple myeloma without amyloidosis. J Nucl Med 1991;32:1785-7. 